Thorax, 1980, 35, 751-753

\title{
Variation in individual responses to the cytotoxicity of cigarette smoke
}

\author{
J M HOPKIN AND C M STEEL \\ From the Medical Research Council Clinical and Population Cytogenetics Unit, \\ Western General Hospital, Edinburgh
}

ABSTRACT There is increasing evidence that elastase may mediate pulmonary damage in emphysema and also that the release of intracellular elastase by cigarette smoke is necessarily associated with cell death. We report consistent and significant variation in response of lymphocytes from different individuals to the cytotoxic effect of cigarette smoke condensate in vitro. This variation which occurred at levels of cigarette smoke likely to be encountered in vivo and which was independent of the age, sex, or smoking habits of the subjects, may be relevant in determining the risk of developing emphysema amongst smokers.

Individual variation in susceptibility to the health hazards associated with smoking is undoubtedly one factor which militates against the success of anti-smoking public health campaigns. It is a relatively neglected aspect of the smoking and health issue but it clearly requires an explanation in medical terms.

In the case of emphysema, family studies indicate that genetic or constitutional factors, other than alpha-1 antitrypsin variants, are involved in determining which smokers will develop the disease. ${ }^{1}$ Currently, the most favoured theory of pathogenesis of emphysema is that the supporting lung tissue is damaged by elastase released from pulmonary alveolar macrophages (PAM) or polymorphonuclear neutrophils (PN $)^{2}$ and, recently, it has been shown that cigarette smoke condensates are cytotoxic to human PN and that this effect is associated with release of elastase from these cells in culture. ${ }^{3}$ Here we report an investigation into possible variation in response of cells from different individuals to the cytotoxic effects of cigarette smoke. We chose peripheral lymphocytes, for while they contain little elastase, they do have an active microsomal enzyme system after PHA transformation, ${ }^{4}$ and therefore might reasonably be expected to reflect the response of metabolically competent cells to a toxic foreign compound.

Address for reprint requests: Dr JM Hopkin, Department of Medicine, The Medical School. University of Birmingham, Vincent Drive, Birmingham B15 2TJ

\section{Methods}

Twelve healthy men (six non-smokers, six inhaling smokers of 20-30 cigarettes per day) aged 20-50 years, were studied.

Lymphocytes were separated from $10 \mathrm{ml}$ of fresh defibrinated blood by sedimentation over Ficoll/Hypaque. ${ }^{5}$ A series of microcultures $\left(10^{4}\right.$ lymphocytes in $100 \mu \mathrm{l}$ ) was set up for each donor in Ham's F10 medium buffered with $12.5 \mathrm{~mm}$ "MOPS" and $0.8 \mathrm{~g} / 1$ bicarbonate and supplemented with $15 \%$ pooled serum from healthy male non-smokers. The response of the lymphocytes to two concentrations $(0.375$ and 0.625 mitogenic units/ml) of purified phytohaemagglutinin (PHA, Wellcome) was measured by the 20 -hour uptake of ${ }^{14} \mathrm{C}$ thymidine on the second, fourth, and sixth days of culture as described previously. ${ }^{6}$ Cigarette smoke condensate was prepared from a popular brand of British cigarette by methods previously published $^{7}$ and the same batch of condensate was used throughout. The effect of condensate on lymphocyte response to PHA was tested by adding various doses dissolved in dimethyl-sulphoxide (DMSO) to the cell suspensions at the start of the culture period. Each combination of PHA concentration, period of culture, and dose of smoke condensate was tested in triplicate for every donor. Control triplicates contained DMSO to the same concentration as those with added smoke condensate. 
In a separate experiment, an additional set of cultures from one donor was tested for cell viability on day 6 by direct counting of the proportion of dye-excluding lymphocytes in a Neubauer haemocytometer after the addition of an equal volume of $0.45 \%$ Nigrosin. $^{8}$

\section{Results and discussion}

Cigarette smoke condensate causes depression of ${ }^{14} \mathrm{C}$ thymidine uptake by PHA-stimulated lymphocytes from all individuals. The effect was consistent for both doses of PHA and at all time points studied and this, together with the findings in relation to cell viability (table) clearly indicates that smoke condensate is producing its effect by direct toxicity to the lymphocytes rather than by binding or chemical inhibition of PHA. The cytotoxic effect was detectable at low concentrations of smoke condensate $(5 \mu \mathrm{g} / \mathrm{ml})$ - this quantity of cigarette smoke condensate representing only the equivalent of $1 / 8000$ of the smoke derived from one of our cigarettes-and at levels, therefore, that might reasonably be expected to

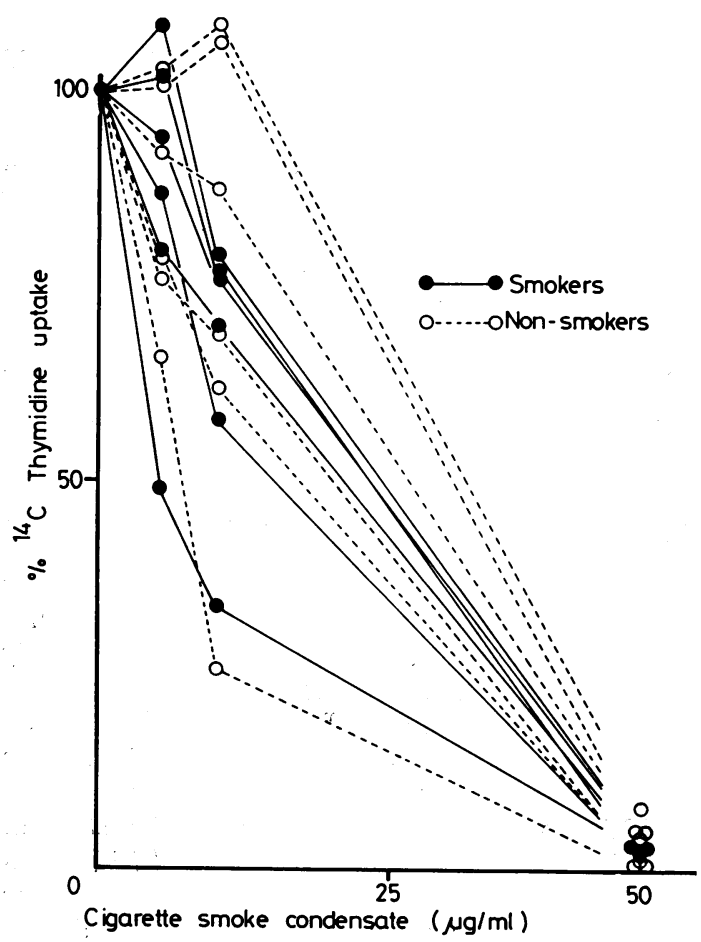

Fig 1 Percentage incorporation of ${ }^{16} \mathrm{C}$ thymidine in lymphocytes from 12 subjects exposed to cigarette smoke condensate.
Table Percentage incorporation of ${ }^{4} \mathrm{C}$ thymidine in lymphocytes and percentage of viable lymphocytes after exposure to cigarette smoke condensate (CSC)

\begin{tabular}{|c|c|c|}
\hline$C S C(\mu g / m l)$ & $\begin{array}{l}\% \text { Dye-excluding } \\
\text { (viable) lymphocytes }\end{array}$ & $\begin{array}{l}\%{ }^{14} C \text { thymidine } \\
\text { incorporation }\end{array}$ \\
\hline 0 & 92 & 100 \\
\hline 5 & 85 & 90 \\
\hline 10 & 75 & 74 \\
\hline 50 & 0 & 4 \\
\hline
\end{tabular}

be achieved in the airways and lung tissues of inhaling cigarette smokers.

As the results in fig 1 illustrate, there is considerable individual variation in lymphocyte sensi-or tivity to the toxic effects of smoke condensate

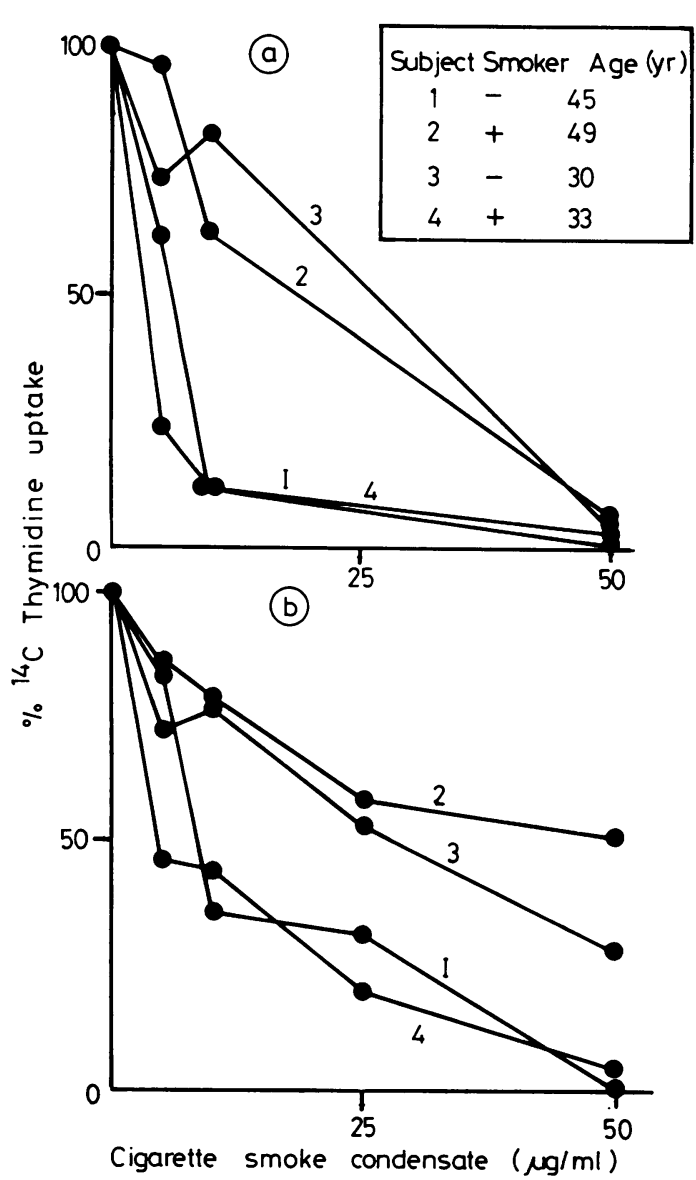

Fig 2 (a) Original and (b) retested responses of four subjects for percentage incorporation of ${ }^{14} \mathrm{C}$ thymidine $\overparen{\mathbb{D}}$ in lymphocytes exposed to cigarette smoke condensate. The slightly enhanced survival of cells from all four individuals on retesting probably reflects some loss of potency of condensate after storage. 
The variation is greatest at a condensate concentration of $10 \mu \mathrm{g} / \mathrm{ml}$, and is not related to age or to smoking status. In fact, the mean of the aggregated absolute scintillation counts were the same for the smoker and and non-smoker groups at all levels of smoke condensate exposure. We retested four of the original subjects after an interval of four months, when only one dose of PHA $(0.625 \mathrm{U} / \mathrm{ml})$ was used and harvesting was performed only on day 6 , and found that differences between sensitive and relatively resistant individuals were consistent (fig 2 ), presumably reflecting innate differences in cellular "sensitivity" to the toxicity of cigarette smoke. The continuous distribution of this variation in response (fig 1) suggests that it results from the interaction of many influences and these may include genetic factors. This would not be surprising for such a complex cellular event as chemically induced cytotoxicity, particularly in a species like man where high rates of protein polymorphism are known to exist. ${ }^{9}$

It is possible that such variation may be relevant in determining the risk to individual smokers of developing emphysema and we are currently exploring this possibility.

We thank the Research Department of Imperial Tobacco Ltd for the loan of the automatic smoking apparatus.

\section{References}

1 Larson ML, Keuppers F, Fudenberg HH. Genetic and environmental determinants of chronic obstructive pulmonary disease. Ann Int Med 1970; 72:627-32.

2 Kuhn C, Senior RM. The role of elastase in the development of emphysema. Lung 1978; 155: 185-97.

3 Blue M, Janoff A. Possible mechanisms of emphysema in cigarette smokers. Am Rev Respir Dis 1978; 117:317-25.

4 Busbee DL, Shaw CR, Cantrell E. Arylhydrocarbon hydroxylase in human lymphocytes. Science 1972; 178:315-6.

5 Harris R, Ukaejiofo EO. Tissue typing using a one step lymphocyte separation procedure. Lancet 1969; 2:327.

6 Steel CM, Creasey GH. A micromethod for the activation of human blood lymphocytes in vitro. Immunol Commun 1976; 5:669-84.

7 Hopkin JM, Evans HJ. Cigarette smoke condensates damage DNA in human lymphocytes. Nature 1979; 279:241-2.

8 Kaltenbach JP, Kaltenbach MH, Lyons WB. Nigrosin as a dye for distinguishing live and dead ascites cells. Exp Cell Res 1968; 15:112-7.

9 Harris H. Enzyme and protein polymorphism in human populations. Br Med Bull 1969; 25:5-13. 